\title{
Genome-wide association study of prevalent and persistent cervical high-risk human papillomavirus (HPV) infection
}

Sally N. Adebamowo ${ }^{1,2^{*}}$ D, Adebowale A. Adeyemo ${ }^{3}$, Charles N. Rotimi ${ }^{3}$, Olayinka Olaniyan ${ }^{4}$, Richard Offiong ${ }^{5}$, Clement A. Adebamowo ${ }^{1,2,6,7}$ and for the H3Africa ACCME Research Group

\begin{abstract}
Background: Genetic factors may influence the susceptibility to high-risk (hr) human papillomavirus (HPV) infection and persistence. We conducted the first genome-wide association study (GWAS) to identify variants associated with cervical hrHPV infection and persistence.

Methods: Participants were 517 Nigerian women evaluated at baseline and 6 months follow-up visits for HPV. HPV was characterized using $\mathrm{SPF}_{10} / \mathrm{LiPA}_{25}$. hrHPV infection was positive if at least one carcinogenic HPV genotype was detected in a sample provided at the baseline visit and persistent if at least one carcinogenic HPV genotype was detected in each of the samples provided at the baseline and follow-up visits. Genotyping was done using the Illumina Multi-Ethnic Genotyping Array (MEGA) and imputation was done using the African Genome Resources Haplotype Reference Panel. Association analysis was done for hrHPV infection (125 cases/392 controls) and for persistent hrHPV infection (51 cases/355 controls) under additive genetic models adjusted for age, HIV status and the first principal component (PC) of the genotypes.

Results: The mean $( \pm S D)$ age of the study participants was $38( \pm 8)$ years, $48 \%$ were HIV negative, $24 \%$ were hrHPV positive and $10 \%$ had persistent hrHPV infections. No single variant reached genome-wide significance $(p<5 X$ $10^{-8}$ ). The top three variants associated with hrHPV infections were intronic variants clustered in KLF12 (all OR: 7.06, $\left.p=1.43 \times 10^{-6}\right)$. The top variants associated with cervical hrHPV persistence were in DAP (OR: 6.86, $\left.p=7.15 \times 10^{-8}\right)$, NR5A2 (OR: $3.65, p=2.03 \times 10^{-7}$ ) and MIR365-2 (OR: 7.71, $p=2.63 \times 10^{-7}$ ) gene regions.

Conclusions: This exploratory GWAS yielded suggestive candidate risk loci for cervical hrHPV infection and persistence. The identified loci have biological annotation and functional data supporting their role in hrHPV infection and persistence. Given our limited sample size, larger discovery and replication studies are warranted to further characterize the reported associations.
\end{abstract}

\footnotetext{
* Correspondence: sadebamowo@som.umaryland.edu

'Department of Epidemiology and Public Health, University of Maryland School of Medicine, 660 West Redwood Street, Howard Hall, Room 119, Baltimore, MD 21201, USA

2University of Maryland Greenebaum Comprehensive Cancer Center, University of Maryland School of Medicine, Baltimore, MD, USA

Full list of author information is available at the end of the article
}

(c) The Author(s). 2020 Open Access This article is licensed under a Creative Commons Attribution 4.0 International License, which permits use, sharing, adaptation, distribution and reproduction in any medium or format, as long as you give appropriate credit to the original author(s) and the source, provide a link to the Creative Commons licence, and indicate if changes were made. The images or other third party material in this article are included in the article's Creative Commons licence, unless indicated otherwise in a credit line to the material. If material is not included in the article's Creative Commons licence and your intended use is not permitted by statutory regulation or exceeds the permitted use, you will need to obtain permission directly from the copyright holder. To view a copy of this licence, visit http://creativecommons.org/licenses/by/4.0/ The Creative Commons Public Domain Dedication waiver (http://creativecommons.org/publicdomain/zero/1.0/) applies to the data made available in this article, unless otherwise stated in a credit line to the data. 


\section{Background}

Human papillomavirus (HPV) is a highly conserved double-stranded DNA virus that has coevolved with human populations for millennia [1]. Over 150 types of HPV have been identified and about 40 types primarily infect stratified cutaneous or mucosal epithelia [2]. HPV infections are among the most common sexually transmitted infections globally [3]. While most infections are cleared naturally by the host's immune system in $\sim 2$ years, the infection persists in about $10 \%$ of those affected [4]. Persistent infection by high-risk (hr) HPV is a risk factor for many epithelial cancers including head and neck, anal and cervical cancers. Susceptibility to cervical hrHPV infection, its persistence and progression to neoplastic disease are determined by epidemiologic and genetic factors. Many epidemiologic risk factors for cervical hrHPV infection including oral contraceptives, cigarette smoking, multiple sexual partners and coinfection with HIV are well documented [5-8], however little is known about the genetic risk factors.

Wang et. al evaluated a panel of 7140 candidate single nucleotide polymorphisms (SNP) in 305 candidate genes/regions selected based on a priori hypotheses of their association with HPV infection and cervical cancer, within the population-based Guanacaste cohort in Costa Rica. They reported that SNPs in Deoxyuridine Triphosphatase (DUT), General Transcription Factor IIH Subunit 4 (GTF2H4), 2'-5' -Oligoadenylate Synthetase 3 (OAS3) and Sulfatase 1 (SULF1) gene regions were associated with HPV persistence, while SNPs in the Transmembrane Channel Like (TMC) 6 and TMC8 gene regions were associated with progression to cervical intraepithelial neoplasia (CIN) 3 and cervical cancer [9]. In a subsequent study in the same cohort, the investigators examined 18,310 SNPs in 1113 genes and reported that SNPs in PRDX3 and RPS19 were associated with HPV persistence and progression from persistent HPV infection to CIN3+ [10]. We examined the association between the aforementioned SNPs and prevalent hrHPV infection in African women, and successfully replicated RPS19:rs2305809 and TYMS:rs2342700 [11].

While the previous candidate gene studies have provided insight into the genetic risk of HPV infection and persistence, agnostic approaches such as genome-wide association studies (GWAS), which interrogate the entire genome would be more useful to uncover novel susceptibility loci for cervical hrHPV infections. A GWAS of cervical hrHPV infection, can also identify novel biomarkers and potential therapeutic targets in cervical cancer, however, none have been conducted to date. We therefore conducted this GWAS of cervical hrHPV infections and tested previously reported associations between genes/regions and prevalent and persistent cervical hrHPV infections.

\section{Methods}

\section{Study population}

We studied 544 women participating in a cohort study of cervical HPV infection and cervical cancer at National Hospital, Abuja and University of Abuja Teaching Hospital, Nigeria, and enrolled between 2012 and 2014, as previously described [5, 12-14]. All the study participants were 18 years of age or older, had a history of vaginal sexual intercourse, were not currently pregnant and had no history of hysterectomy. We collected data on socio-demographic characteristics, sexual and reproductive history, and confirmed participants' HIV status from hospital medical records at study entry. Participants were asked to return for follow-up visits after 6 months, at which time, the history, physical examinations and sample collections were repeated. We collected venous blood samples and performed pelvic examinations on all the study participants at each study visit. Elution swab system (Copan, Italy) was used to collect exfoliated cervical cells, which were inserted in $1 \mathrm{ml}$ Amies' transport media (Copan).

\section{HPV detection by $\mathrm{SPF}_{10} / \mathrm{LiPA}_{25}$}

We extracted DNA from the cervical exfoliated cells as previously described [11]. Samples were tested for HPV DNA by hybridization of $\mathrm{SPF}_{10}$ amplimers to a mixture of general HPV probes recognizing a broad range of high-risk, low-risk, and possible hrHPV genotypes in a microtiter plate format, as described previously [15]. All samples determined to be HPV DNA positive by $\mathrm{SPF}_{10}$ DNA Enzyme Immunoassay (DEIA) were genotyped using the $\mathrm{LiPA}_{25}$ version 1 . The $\mathrm{LiPA}_{25}$ assay provides type-specific information for 25 different HPV genotypes simultaneously and identifies infection by one or more of 13 hrHPV genotypes: 16, 18, 31, 33, 35, 39, 45, 51, 52, $56,58,59$, and $68[16,17]$. However, as this assay does not differentiate between HPV 68 and 73, we defined this HPV genotype (i.e. HPV68/73) as low-risk. We defined hrHPV infection as prevalent if at least one hrHPV genotype was detected in the baseline sample and persistent if at least one hrHPV genotype was detected in samples provided at both the baseline and follow-up visits. We defined persistently negative as absence of hrHPV genotype in the baseline and followup visit samples.

\section{Genotyping and imputation}

Samples from the study participants were genotyped using the Illumina Multi-Ethnic Global Array (MEGA) which has $\sim 1.7$ million markers. Sample-level genotype call rate was at least 0.95 for all the study participants. We filtered out from the genotyped dataset SNPs that did not meet the following criteria: autosomal SNPs 
$(n=78,713)$, variant missingness $<0.05 \quad(n=96,410)$, Hardy-Weinberg equilibrium (HWE) $p>1 \times 10-6 \quad(n=$ 7692) and minor allele frequency (MAF) $>=0.01(n=$ 564,791). The resulting 958,363 SNPs that passed these quality control filters had a SNP success rate of 0.9985 and were used as the basis for imputation.

Imputation was performed using the Sanger Imputation Service (https://imputation.sanger.ac.uk/) [18]. Prephasing was done with the Eagle2 algorithm [19] and imputation was done with positional Burrows-Wheeler transform (PBWT) [20]. The reference panel used was the African Genome Resources Haplotype Reference Panel, an African genome imputation reference panel based on 9912 haplotypes (4956 samples) which includes all African and non-African 1000 Genomes Phase 3 populations and additional African genomes from Uganda, Ethiopia, Egypt, Namibia and South Africa (including 2298 African samples with whole genome sequence data from the African Genome Variation Project (AGVP) [21] and the Uganda 2000 Genomes Project (UG2G) [22]. The IMPUTE2 INFO score was used as a quality metric to evaluate the uncertainty in genotype imputation. Imputation yielded a total number of $\sim 104$ million markers. We filtered the resulting imputation dataset for variants with info score $\geq$ 0.3 and MAF $\geq 0.01$, with a final set of $\sim 18$ million SNPs which was used for association analysis.

\section{Statistical analysis}

From the original set of 544 women, we excluded 27 women from the baseline analyses because of incomplete data (5 missing HPV, 22 missing both HPV and HIV results), leaving only 517 women in the baseline analyses. Of the 517 women, we excluded those who did not return for the follow-up visit ( $n=$ 9), those with missing HPV results $(n=35)$ and included the remaining 473 women in the analyses for persistent hrHPV infections. For the prevalent hrHPV analysis, we compared 125 women with cervical hrHPV infections (cases) to 392 women without cervical hrHPV infections at baseline (controls). For the persistent hrHPV analysis, we compared 51 women with hrHPV infection at both the baseline and follow-up visits (cases) to 355 women without hrHPV infections at either the baseline or follow-up visits (controls). Using LD-pruned SNP genotype data available on the same women, we computed principal components based on the variancestandardized relationship matrix with PLINK 1.9 [23, 24] using the parameters "--indep 5052 ", namely with a window size of 50 SNPs, 5 SNPs to shift the window at each step and a variance inflation factor of 2. We found that the first principal component was significant in the test for population differentiation and included it in downstream association analyses. The association between the genetic variants and prevalent or persistent hrHPV infection was estimated using unconditional multivariate logistic regression, assuming an additive genetic model adjusted for age, HIV status and the first principal component. Genome-wide significance was set at $p$ value $<5 \times 10^{-8}$. We used an additive genetic model adjusted for HIV status to test for replication of SNPs associated with HPV and cervical neoplasia in other populations and considered $p$-values $<0.05$ as statistically significant evidence for replication. The analyses were conducted using PLINK.

\section{Results}

The mean $( \pm \mathrm{SD})$ age of the participants was $38( \pm 8)$ years while their mean $( \pm S D)$ body mass index (BMI $\left.\left[\mathrm{kg} / \mathrm{m}^{2}\right]\right)$ was $27( \pm 6)$. About half of the participants were HIV positive (52\%, 270/517), 24\% (125/517) had prevalent cervical hrHPV infections at baseline and 11\% (51/473) had persistent hrHPV infections. The distribution of type-specific prevalent and persistent cervical hrHPV infections is shown in Table 1. Non HPV16/18 were more prevalent in the study population. The prevalence of HPV16 and HPV18 in the study population were $2 \%(10 / 517)$ and $4 \%(8 /$ $517)$, respectively. About $8 \%(10 / 125)$ of the women with cervical hrHPV infections had HPV16 and 16\% (20/125) had HPV18 at baseline. HPV52 and HPV35 were the most prevalent HPV genotypes in the study population. About $7 \%(37 / 517)$ of the study population had HPV52, which accounted for about a third of the HPV positive infections at baseline. HPV52 and HPV35 were also more likely to persist, compared to the other hrHPV types. About 19\% of the participants had single cervical hrHPV infections and $\sim 9 \%$ of the participants had multiple cervical hrHPV infections at both visits. Participants returned for follow-up visits at a median (IQR) time of 5.7 (5.4-7.5) months.

The Manhattan plot, Fig. 1, shows all the SNPs and Table 2 shows the top 20 SNPs associated with prevalent cervical hrHPV infections. A cluster of SNPs $\left(D^{\prime}=1\right.$, $\left.r^{2}=1\right)$ located on chromosome 13, rs149473200, rs147344426 and rs151071053 (Odds Ratio [OR], $p$-value for all SNPs was OR: 7.06, $p=1.43 \times 10^{-6}$ ), had the strongest association with cervical prevalent hrHPV. The regional plot for rs149473200 in Fig. 1 shows that the cluster of SNPs are intronic in Krüppel-like Factor 12 gene (KLF12) and shows the surrounding markers. SNPs near Long Intergenic Non-Protein Coding RNA 290 gene (NCRNA00290) also had a borderline genome-wide significant association with prevalent hrHPV.

The SNP with the strongest association was located on Chr5:10847898, OR: $6.86, p=7.15 \times 10^{-8}$, Table 3. This 
Table 1 Distribution of Type-Specific Prevalent and Persistent Cervical High-Risk (hr) HPV Infections by HIV status

\begin{tabular}{|c|c|c|c|c|c|c|}
\hline \multirow[t]{2}{*}{ HPV Type } & \multicolumn{3}{|c|}{ Prevalent Infections } & \multicolumn{3}{|c|}{ Persistent Infections } \\
\hline & $\begin{array}{l}\text { Total } \\
n=517\end{array}$ & $\begin{array}{l}\text { HIV Negative } \\
n=247\end{array}$ & $\begin{array}{l}\text { HIV Positive } \\
n=270\end{array}$ & $\begin{array}{l}\text { Total } \\
n=473\end{array}$ & $\begin{array}{l}\text { HIV Negative } \\
n=223\end{array}$ & $\begin{array}{l}\text { HIV Positive } \\
n=250\end{array}$ \\
\hline hrHPV Positive & $125(24.2 \%)$ & 37 (14.9\%) & $88(32.6 \%)$ & $51(10.8 \%)$ & $10(0.0 \%)$ & $41(1.8 \%)$ \\
\hline HPV 16 & $10(1.9 \%)$ & $2(0.8 \%)$ & $8(2.9 \%)$ & $4(0.9 \%)$ & $0(0.0 \%)$ & $4(1.6 \%)$ \\
\hline HPV 18 & $20(3.9 \%)$ & $5(2.0 \%)$ & $15(5.5 \%)$ & $5(1.1 \%)$ & $0(0.0 \%)$ & $5(2.0 \%)$ \\
\hline HPV 31 & $11(2.1 \%)$ & $1(0.4 \%)$ & $10(3.7 \%)$ & $6(1.3 \%)$ & $1(0.5 \%)$ & $5(2.0 \%)$ \\
\hline HPV 33 & $16(3.1 \%)$ & $3(1.2 \%)$ & $13(4.8 \%)$ & $4(0.9 \%)$ & $1(0.5 \%)$ & $3(1.2 \%)$ \\
\hline HPV 35 & 27 (5.2\%) & $5(2.0 \%)$ & $22(8.1 \%)$ & $14(3.0 \%)$ & $3(1.4 \%)$ & $11(4.4 \%)$ \\
\hline HPV 39 & $7(1.3 \%)$ & $2(0.8 \%)$ & $5(1.8 \%)$ & $2(0.4 \%)$ & $0(0.0 \%)$ & $2(0.8 \%)$ \\
\hline HPV 45 & $9(1.7 \%)$ & $4(1.6 \%)$ & $5(1.8 \%)$ & $1(0.2 \%)$ & $0(0.0 \%)$ & $1(0.4 \%)$ \\
\hline HPV 51 & $9(1.7 \%)$ & $1(0.4 \%)$ & $8(2.9 \%)$ & $3(0.6 \%)$ & $0(0.0 \%)$ & $3(1.2 \%)$ \\
\hline HPV 52 & 37 (7.1\%) & $12(4.8 \%)$ & $25(9.2 \%)$ & $18(3.8 \%)$ & $5(2.2 \%)$ & $13(5.2 \%)$ \\
\hline HPV 56 & $9(1.7 \%)$ & $4(1.6 \%)$ & $5(1.8 \%)$ & $1(0.2 \%)$ & $0(0.0 \%)$ & $1(0.4 \%)$ \\
\hline HPV 58 & $10(1.9 \%)$ & $2(0.8 \%)$ & $8(2.9 \%)$ & $3(0.6 \%)$ & $1(0.5 \%)$ & $2(0.8 \%)$ \\
\hline HPV 59 & $7(1.3 \%)$ & $0(0.0 \%)$ & $7(2.5 \%)$ & $0(0.0 \%)$ & $0(0.0 \%)$ & $0(0.0 \%)$ \\
\hline
\end{tabular}

The table shows the number (percentage) of participants who were high-risk HPV positive at baseline

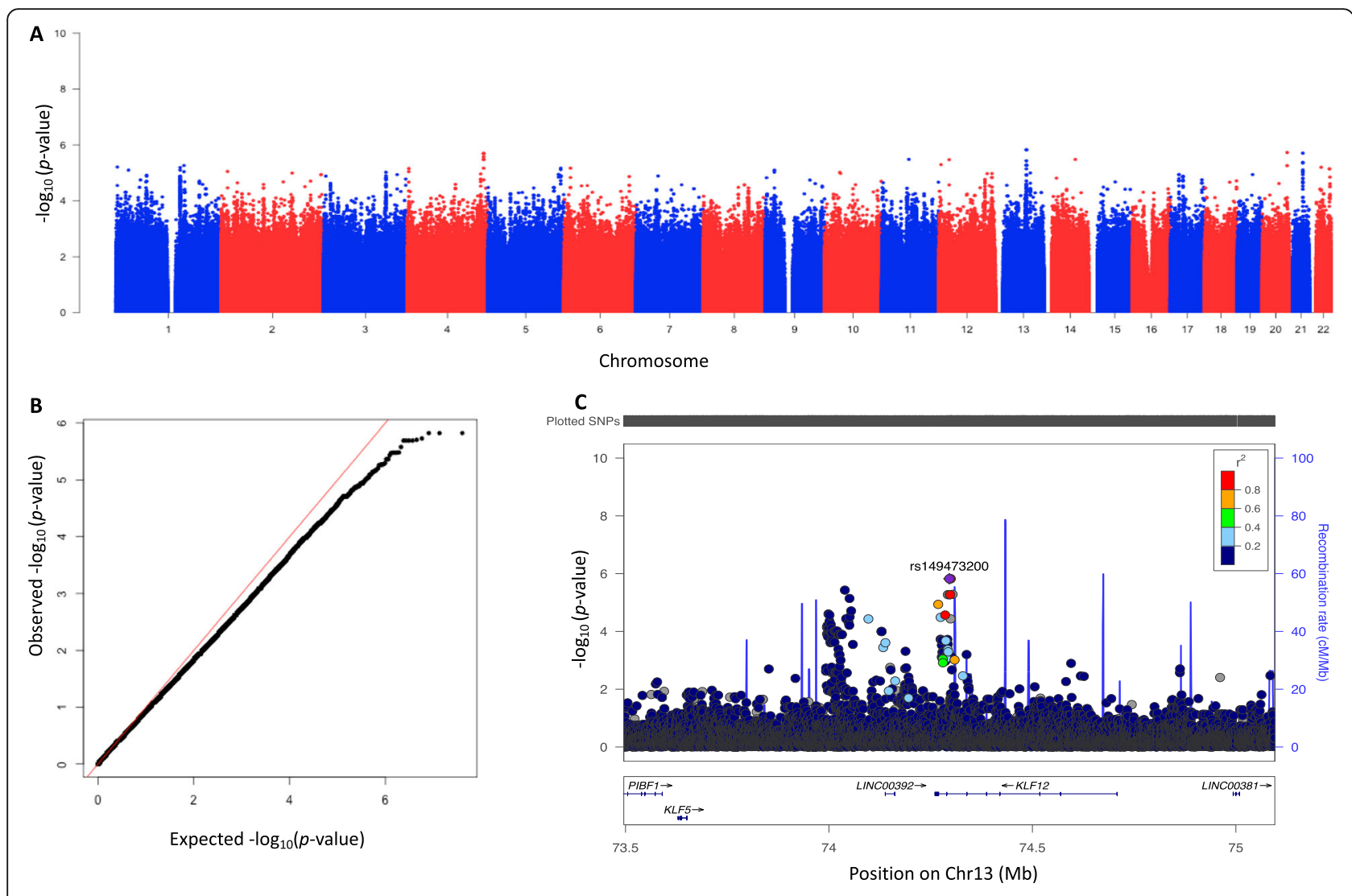

Fig. 1 Genome-wide association results for prevalent high-risk HPV. $\lambda=1.02$. a Manhattan plot (b) Quantile-quantile plot (c) Regional plot for rs149473200 
Table 2 Associations of the Top 20 SNPS with Prevalent Cervical high-risk Infections

\begin{tabular}{|c|c|c|c|c|c|c|c|c|}
\hline SNP & Chr & Base Position & Near gene & Reference allele & MAF & OR & $95 \% \mathrm{Cl}$ & $P$-value \\
\hline rs149473200 & 13 & $74,295,767$ & KLF12 & $G$ & 0.03 & 7.06 & $3.19-15.63$ & $1.43 \times 10^{-6}$ \\
\hline rs147344426 & 13 & $74,298,464$ & KLF12 & G & 0.03 & 7.06 & 3.19-15.63 & $1.43 \times 10^{-6}$ \\
\hline rs151071053 & 13 & $74,299,405$ & KLF12 & $\mathrm{T}$ & 0.03 & 7.06 & $3.19-15.63$ & $1.43 \times 10^{-6}$ \\
\hline rs572823632 & 13 & $74,299,732$ & $K L F 12^{\mathrm{a}}$ & GAA & 0.03 & 7.06 & $3.19-15.63$ & $1.43 \times 10^{-6}$ \\
\hline rs73010973 & 4 & $181,310,690$ & NCRNA00290 & $\mathrm{T}$ & 0.06 & 3.86 & $2.22-6.72$ & $1.70 \times 10^{-6}$ \\
\hline rs73010975 & 4 & $181,310,704$ & NCRNA00290 & T & 0.06 & 3.86 & $2.22-6.72$ & $1.70 \times 10^{-6}$ \\
\hline rs74739185 & 4 & $181,311,019$ & NCRNA00290 & G & 0.06 & 3.86 & $2.22-6.72$ & $1.70 \times 10^{-6}$ \\
\hline rs79140020 & 4 & $181,311,020$ & NCRNA00290 & T & 0.06 & 3.86 & $2.22-6.72$ & $1.70 \times 10^{-6}$ \\
\hline rs35833676 & 21 & $32,961,256$ & TIAMI & C & 0.07 & 3.45 & $2.07-5.73$ & $1.79 \times 10^{-6}$ \\
\hline rs3818252 & 20 & $58,675,675$ & C20orf197 & C & 0.57 & 2.22 & $1.60-3.10$ & $2.06 \times 10^{-6}$ \\
\hline rs112893815 & 4 & $181,311,254$ & NCRNA00290 & C & 0.06 & 3.77 & $2.17-6.53$ & $2.22 \times 10^{-6}$ \\
\hline- & 8 & $74,725,256$ & $U B E 2 W^{A}$ & G & - & 3.31 & $2.01-5.44$ & $2.42 \times 10^{-6}$ \\
\hline rs506594 & 11 & $64,162,897$ & RPS6KA4 & T & 0.77 & 0.44 & $0.31-0.62$ & $2.67 \times 10^{-6}$ \\
\hline rs73010952 & 4 & $181,308,382$ & NCRNA00290 & G & 0.06 & 3.69 & $2.14-6.38$ & $2.77 \times 10^{-6}$ \\
\hline rs111800742 & 4 & $181,308,587$ & NCRNA00290 & C & 0.06 & 3.69 & $2.14-6.38$ & $2.77 \times 10^{-6}$ \\
\hline rs73010957 & 4 & $181,309,080$ & NCRNA00290 & A & 0.06 & 3.69 & $2.14-6.38$ & $2.77 \times 10^{-6}$ \\
\hline rs6574170 & 14 & $74,729,207$ & VSX2 & A & 0.04 & 5.29 & $2.63-10.67$ & $3.16 \times 10^{-6}$ \\
\hline- & 17 & $36,374,963$ & LOC440434 & TA & - & 0.48 & $0.35-0.65$ & $3.17 \times 10^{-6}$ \\
\hline rs17090215 & 13 & $74,039,057$ & KLF12 & C & 0.05 & 3.90 & $2.20-6.92$ & $3.21 \times 10^{-6}$ \\
\hline rs375435036 & 1 & $72,615,562$ & $N E G R 1^{\mathrm{a}}$ & C & 0.15 & 2.52 & $1.71-3.73$ & $3.49 \times 10^{-6}$ \\
\hline
\end{tabular}

For this analysis, 125 women with cervical hrHPV infections were compared to 392 women without cervical hrHPV infections at baseline. Base positions were

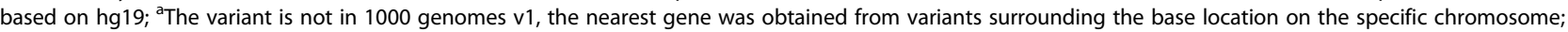
Odds Ratio (OR) and 95\% Confidence Intervals (CI) were estimated using an additive genetic model; Models were adjusted for age, HIV status and the first principal components of the genotypes

variant has not been included in the 1000 Genomes data resources. However, we found that the variants surrounding this region, Chr5:10847888-10,847,902, are located between Death Associated Protein gene (DAP) and Catenin Delta 2 (CTNND2) genes. Figure 2 shows a Manhattan plot and a regional plot of association with persistent cervical hrHPV infections. Other top variants associated with persistent hrHPV infections were rs200516199 upstream of MicroRNA 365b gene (MIR365-2), OR: 7.71, $p=2.63 \times 10^{-7}$; variants clustered upstream of Nuclear Receptor Subfamily 5 Group A Member 2 gene (NR5A2) and Junctophilin Type 2 gene (JPH2). Next, we conducted a replication study by identifying all SNPs associated with HPV and cervical neoplasia in other studies (Supplementary Table 1) and evaluated their association with hrHPV in the present study, using an adjusted additive genetic model. We found rs9893818 (OR: 0.88, $p=0.58$ for prevalent hrHPV; OR: 0.92, $p=0.82$ for persistent hrHPV) and rs2299187 (OR: 0.95, $p=0.86$ for prevalent hrHPV; OR: 1.13, $p=0.71$ for persistent hrHPV) in our dataset but they were not significantly associated with prevalent or persistent cervical hrHPV infections (Supplemental Table 2). Lastly, we conducted stratified analysis by HIV status and found that none of the variants reached genomewide statistical significance (Supplemental Tables 3 and 4).

\section{Discussion}

This is the first GWAS of cervical hrHPV infection, to our knowledge. The top three variants associated with prevalent cervical hrHPV infection were clustered in $K L F 12$, while those associated with persistent cervical hrHPV infection were near DAP, CTNND2, MIR365-2 and NR5A2. These associations were borderline genome-wide significant. It is well established that the determinants of prevalent and persistent cervical hrHPV infections are different. Our finding of separate variants associated with prevalent and persistent cervical hrHPV suggests that their genetic risk factors may also differ.

The associated SNPs in KLF12, rs149473200 and rs147344426, are eQTLs of CD3e molecule (CD3E), a protein coding gene which plays an essential role in T-cell development and its defects cause immunodeficiency. KLF12, a protein coding gene, is overexpressed in human $\mathrm{B}$ and $\mathrm{T}$ lymphocytes, CD8 T cells and natural killer cells [25]. These cells play important roles during immune response to hrHPV infection, including recognizing and destroying infected cells. hrHPV causes the immune system to become 
Table 3 Associations of the Top 20 SNPS with Persistent Cervical high-risk Infections

\begin{tabular}{|c|c|c|c|c|c|c|c|c|}
\hline SNP & Chr & Base Position & Near gene & Reference allele & MAF & OR & $95 \% \mathrm{Cl}$ & $P$-value \\
\hline- & 5 & $10,847,898$ & $D A P^{a}$ & $C$ & - & 6.87 & $3.41-13.84$ & $7.15 \times 10^{-8}$ \\
\hline rs143668247 & 1 & $199,701,882$ & NR5A2 & C & 0.35 & 3.66 & $2.24-5.97$ & $2.03 \times 10^{-7}$ \\
\hline rs200516199 & 17 & $29,917,727$ & MIR365-2 & $\pi T G A$ & 0.04 & 7.71 & $3.54-16.78$ & $2.63 \times 10^{-7}$ \\
\hline rs116834259 & 20 & $42,742,258$ & $\mathrm{JPH} 2$ & $\mathrm{~T}$ & 0.11 & 4.42 & $2.50-7.81$ & $3.15 \times 10^{-7}$ \\
\hline rs11452236 & 20 & $42,751,590$ & $\mathrm{JPH} 2$ & C & 0.13 & 4.03 & $2.34-6.92$ & $4.78 \times 10^{-7}$ \\
\hline rs74358070 & 20 & $42,727,587$ & $\mathrm{JPH} 2$ & $\mathrm{~T}$ & 0.11 & 4.24 & $2.41-7.47$ & $5.52 \times 10^{-7}$ \\
\hline rs16832308 & 2 & $133,253,243$ & GPR390 & A & 0.04 & 6.30 & $3.05-13.01$ & $6.49 \times 10^{-7}$ \\
\hline rs62167448 & 2 & $133,254,091$ & GPR39 & C & 0.04 & 6.30 & $3.05-13.01$ & $6.49 \times 10^{-7}$ \\
\hline rs150410476 & 11 & $37,223,676$ & C110rf74 & A & 0.03 & 8.31 & $3.60-19.16$ & $6.80 \times 10^{-7}$ \\
\hline rs12740341 & 1 & $199,699,781$ & NR5A2 & C & 0.26 & 3.18 & $2.01-5.03$ & $7.94 \times 10^{-7}$ \\
\hline rs79032354 & 20 & $42,732,460$ & $\mathrm{JPH} 2$ & C & 0.13 & 3.91 & $2.27-6.71$ & $7.96 \times 10^{-7}$ \\
\hline rs6130527 & 20 & $42,733,946$ & $\mathrm{JPH} 2$ & G & 0.13 & 3.91 & $2.27-6.71$ & $7.96 \times 10^{-7}$ \\
\hline rs4810411 & 20 & $42,751,472$ & $\mathrm{JPH} 2$ & C & 0.13 & 3.81 & $2.24-6.50$ & $7.99 \times 10^{-7}$ \\
\hline rs2502139 & 1 & $199,695,633$ & NR5A2 & A & 0.27 & 3.17 & $2.00-5.02$ & $8.94 \times 10^{-7}$ \\
\hline rs34026413 & 1 & $199,695,074$ & NR5A2 & A & 0.27 & 3.10 & $1.97-4.88$ & $7.94 \times 10^{-6}$ \\
\hline- & 1 & $26,304,144$ & PAFAH $2^{\mathrm{a}}$ & C & - & 10.19 & $4.01-25.92$ & $7.94 \times 10^{-6}$ \\
\hline rs543084794 & 2 & $133,250,145$ & GPR39 & C & 0.04 & 6.44 & $3.04-13.65$ & $7.94 \times 10^{-6}$ \\
\hline rs79014529 & 20 & $42,717,781$ & TOX2 & C & 0.13 & 3.81 & $2.22-6.53$ & $7.94 \times 10^{-6}$ \\
\hline rs1429702 & 1 & $199,694,059$ & NR5A2 & $\mathrm{T}$ & 0.27 & 3.10 & $1.96-4.87$ & $7.94 \times 10^{-6}$ \\
\hline rs6130520 & 20 & $42,716,399$ & TOX2 & G & 0.13 & 3.77 & $2.20-6.47$ & $7.94 \times 10^{-6}$ \\
\hline
\end{tabular}

For this analysis, 51 women with hrHPV infection at both the baseline and follow-up visits were compared to 355 women without hrHPV infections at either the baseline or follow-up visits. Base positions were based on hg19; ${ }^{a}$ The variant is not in 1000 genomes v1, the nearest gene was obtained from variants surrounding the base location on the specific chromosome; Odds Ratio (OR) and 95\% Confidence Intervals (Cl) were estimated using an additive genetic model; Models were adjusted for age, HIV status and the first principal components of the genotypes

more tolerant to infection by avoiding cytolysis of host cells, inhibiting interferon synthesis and cytotoxic $\mathrm{T}$ cell function, and inducing regulatory $\mathrm{T}$ cell infiltration [26-28]. This creates a cervical microenvironment that is susceptible to persistent infection and carcinogenesis. KLF12 has been linked to several cancers [29-32], including head and neck cancers $[33,34]$, which are usually associated with hrHPV. A study of HPV integration breakpoints in the human genome showed that a copy of the virus was integrated between KLF5 and KLF12 in HPV-positive SiHa cells [35]. Recently, a whole-genome sequencing study on HPV-positive $\mathrm{SiHa}$, HeLa and cervical carcinoma cells showed $K L F 12$ was one of the top three integration sites for HPV [36]. Thus, KLF12 may play a major role in the underlying mechanisms that lead to hrHPV infection, persistence and cervical carcinogenesis.

A locus between CTNND2 and DAP in the short arm of chromosome 5, had the strongest association with persistent cervical hrHPV infections in the present study. CTNND2 gene encodes an adhesive junction associated protein and is overexpressed in the cervix [25]. It has been implicated in cancer formation and has been linked to breast and ovarian cancers [37-39]. DAP encodes a basic, proline-rich protein which acts as a positive mediator of programmed cell death that is induced by interferon-gamma [40]. It negatively regulates autophagy and is a substrate for mammalian target of rapamycin (mTOR) [41], which regulates different cellular processes. Results from GWASs show that DAP is associated with digestive disorders, gut microbiota, height and obesity [42-45]. There is some evidence that this gene plays a pro-apoptotic role in breast and cervical cancers [46-48]. Esteller et. al. showed that hypermethylation of the $\mathrm{CpG}$ islands located in the promoter region of $D A P$ leads to transcriptional silencing thereby enabling malignant growth [49].

rs200516199 and rs143668247 near MIR365-2 and NR5A2 (LRH-1), respectively, were also associated with persistent cervical hrHPV infections. Like CTNND2 and $D A P, M I R 365-2$ has also been linked to breast and cervical cancers $[50,51]$. It appears to have an oncogenic effect in some cancers $[52,53]$ and tumor suppressor effect in others [54-57]. Bioinformatics and experimental research studies have proved that apoptotic markers BAX and BCL-2, are two of the main targets of this microRNA [58, 59]. rs143668247 alters motifs in POU Class 5 Homeobox 1 (POU5F1) gene. Aberrant expression of this gene in adult tissues is associated with tumorigenesis 

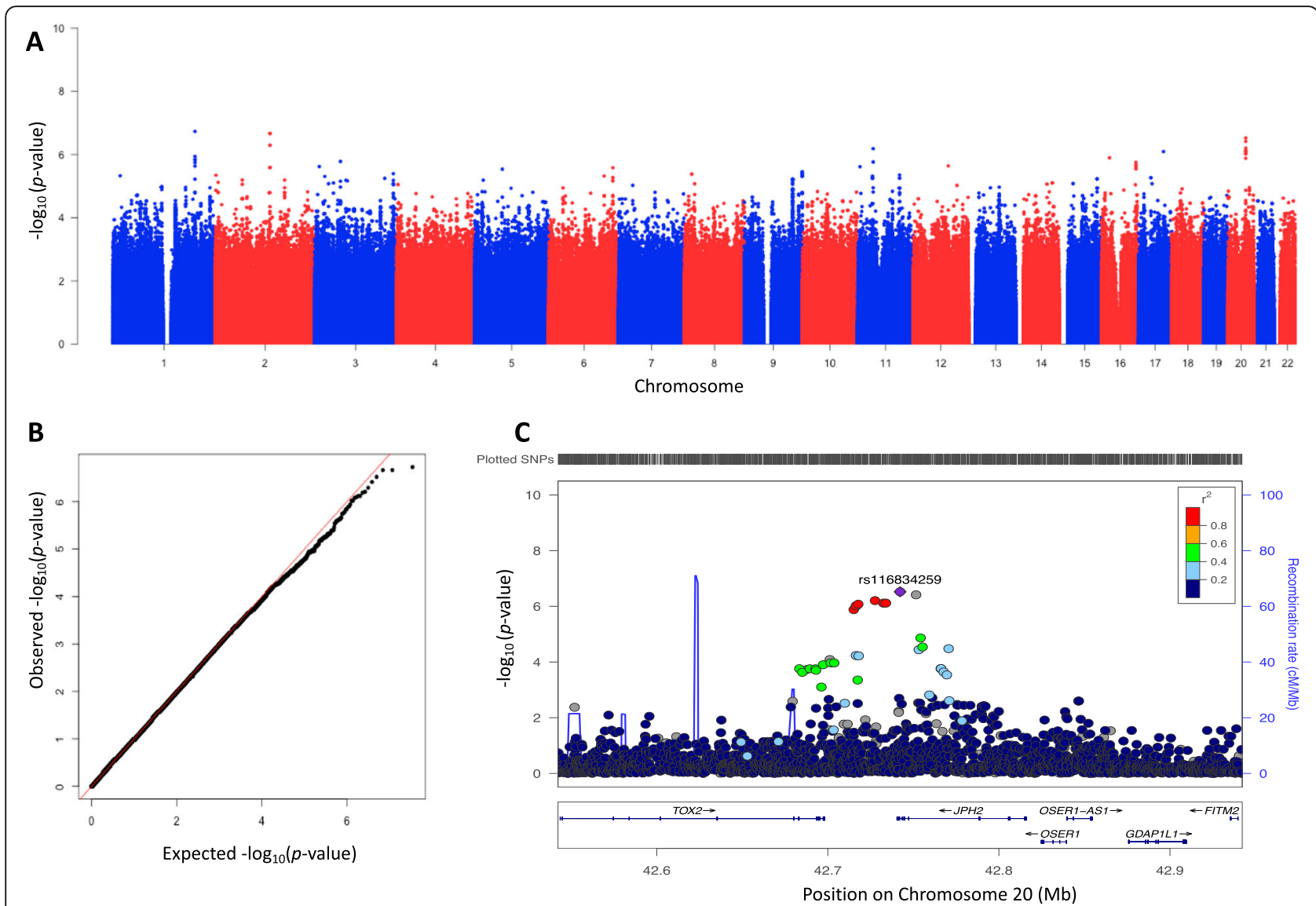

Fig. 2 Genome-wide association results for persistent high-risk HPV. $\lambda=1.00$. a Manhattan plot (b) Quantile-quantile plot (c) Regional plot for rs 116834259

[37]. rs143668247 is located $295 \mathrm{~kb} 5^{\prime}$ of $N R 5 A 2$, an orphan receptor recently identified as a negative modulator of hepatic inflammatory processes [60]. It encodes a protein which is highly expressed in the liver and is involved in regulating the expression of genes for lipid metabolism, hepatitis B virus [61, 62] and several cancers [63-69]. Although these genes have not been previously linked to HPV infection, subsequent GWAS may confirm our findings.

Our study is limited by its exploratory nature. Given the small sample size of this study the power of the study was limited. Thus, we may have missed associations with smaller effect sizes and we could not examine the relationship between variants and type-specific hrHPV and by HIV status. Our replication study yielded two SNPs, TMC6/TMC8:rs9893818 which was reported to be associated with CIN3/cervical cancer [9] and CACNA2D1:rs2299187, which was associated with survival of head and neck squamous cell carcinoma in a recent GWAS [70]. However, these variants were not associated with hrHPV in our study. Also, rs7082598 variant in PRDX3 and rs2305809 variant in RPS19, which were shown to be associated with HPV persistence in a candidate gene study conducted within Guanacaste cohort in Costa Rica, were not associated with hrHPV in our study. This may be due to inadequate sample size, variability in the types of hrHPV or population differences. Unlike our study population which was comprised of only African women, the population of Guanacaste is heavily admixed and has been described as being composed mainly of European (42.5\%) and $\mathrm{Na}$ tive American (38.3\%) ancestries, with considerable African influence (15.2\%) and a small influence from Asians (4\%) [71]. The frequency of rs7082598 is 0.14 (AFR), 0.11 (AMR), 0.04 (ASN) and 0.08 (EUR) [72], our study may have been underpowered to detect an association with this variant. The frequency of rs2305809 is 0.89 (AFR), 0.52 (AMR), 0.56 (ASN) and 0.48 (EUR) [72], suggesting that most African women have this variant regardless of their HPV status, which is most likely why we were unable to detect an association between rs2305809 and HPV in our study population. The findings from this exploratory study suggests that there are significant associations between genetic variants and 
cervical hrHPV infection and larger studies are warranted. The strengths of our study include studying a well-characterized longitudinal cohort with multiple hrHPV assessments in the participants. Secondly, the main loci identified have biological and functional support for a role in HPV infection and persistence. Lastly, the variant frequencies we observed were similar between our samples and those of west African ancestry samples in the 1000 Genomes dataset, validating the genotype accuracy in our datasets.

\section{Conclusion}

In conclusion, our study yielded suggestive genetic risk factors for prevalent and persistent cervical hrHPV infections. Further investigations of genetic variation in the KLF12, CTNND2 and DAP genes may provide insight into mechanisms of susceptibility to hrHPV infection and persistence. Larger discovery and replication studies are warranted to confirm these findings.

\section{Supplementary Information}

The online version contains supplementary material available at https://doi. org/10.1186/s12881-020-01156-1.

\section{Additional file 1: Supplemental Table S1. \\ Additional file 2: Supplemental Table S2. Replication of SNPS Associated with Cervical high-risk Infections.}

Additional file 3: Supplemental Table S3. Associations of the Top SNPS with Cervical High-risk Infections in HIV-Negative Women.

Additional file 4: Supplemental Table S4. Associations of the Top SNPS with Cervical High-risk Infections in HIV-Positive Women.

Additional file 5: Supplementary Figure S1. Principal components (PC) plot of the genotypes of the study participants.

\section{Abbreviations}

AGVP: African Genome Variation Project; BMI: Body mass index; CIN: Cervical intraepithelial neoplasia; DEIA: DNA Enzyme Immunoassay; GWAS: Genomewide association studies; HPV: Human papillomavirus; hrHPV: High-risk Human Papillomavirus; HWE: Hardy-Weinberg equilibrium; IQR: Interquartile range: MAF: Minor allele frequency; MEGA: Multi-Ethnic Global Array: OR: Odds ratio; PBWT: Positional Burrows-Wheeler transform; SNP: Single nucleotide polymorphisms; UG2G: Uganda 2000 Genomes Project

\section{Acknowledgments}

We are very grateful to the women who participated in this study. We acknowledge the past and present members of the H3Africa ACCME Research Group, Research Associates and Volunteers who contributed to this study, especially Dareng E, Famooto A, Obende K, Adebayo A, Ologun S, Alabi B, Achara P, Bakare R, Dakum P. The content is solely the responsibility of the authors and does not necessarily represent the official views of the National Cancer Institute, or the National Institutes of Health.

\section{Authors' contributions}

SA analyzed the data, interpreted the results and drafted the manuscript. AA contributed to the data analysis. $\mathrm{OO}$ and $\mathrm{RO}$ provided clinical oversight for the study. CA obtained funding for this study. AA, OO, RO, CR and CA provided critical revisions to the manuscript. All the authors contributed to the study implementation and approved the final version of the manuscript.

\section{Funding}

This work was supported by the UM-Capacity Development for Research in AIDS Associated Malignancy Grant (NIH/NCI 1D43CA153792-01) and African
Collaborative Center for Microbiome and Genomics Research Grant (NIH/ NHGRI 1U54HG006947). Sally Adebamowo is funded by the American Cancer Society IRG-18-160-16.

The funders had no role in study design, data collection and analysis, decision to publish, or preparation of the manuscripts.

\section{Availability of data and materials}

The datasets used and/or analyzed during the current study are available from the corresponding author on reasonable request.

\section{Ethics approval and consent to participate}

The study was conducted according to the Nigerian National Code for Health Research Ethics. Ethical approval to conduct this study was obtained from the Institute of Human Virology Nigeria research ethics committee and University of Maryland School of Medicine Institutional Review Board. Written informed consent was obtained from all participants before enrollment in the study.

Consent for publication

Not applicable.

\section{Competing interests}

The authors declare that they have no competing interests.

\section{Author details}

'Department of Epidemiology and Public Health, University of Maryland School of Medicine, 660 West Redwood Street, Howard Hall, Room 119, Baltimore, MD 21201, USA. ${ }^{2}$ University of Maryland Greenebaum Comprehensive Cancer Center, University of Maryland School of Medicine, Baltimore, MD, USA. ${ }^{3}$ Center for Research on Genomics and Global Health, National Human Genome Research Institute, National Institutes of Health, Bethesda, MD, USA. ${ }^{4}$ Department of Obstetrics and Gynecology, National Hospital Abuja, Abuja, Nigeria. ${ }^{5}$ Department of Obstetrics and Gynecology, University of Abuja Teaching Hospital, Abuja, Nigeria. Institute of Human Virology, University of Maryland School of Medicine, Baltimore, MD, USA. ${ }^{7}$ Institute of Human Virology Nigeria, Abuja, Nigeria.

Received: 8 September 2019 Accepted: 25 October 2020

Published online: 23 November 2020

\section{References}

1. Van Doorslaer K. Evolution of the papillomaviridae. Virology. 2013;445(1-2): $11-20$.

2. IARC. Monographs on the evaluation of carcinogenic risks to humans: biological agents, a review of human carcinogenesis. Lyon: International Agency for Research on Cancer; 2012. [Cited 2017 January 2017]. Available from: http://monographs.iarc.fr/ENG/Monographs/vol100B/mono100B-11.pdf.

3. Bosch FX, Burchell AN, Schiffman M, Giuliano AR, de Sanjose S, Bruni L, et al. Epidemiology and natural history of human papillomavirus infections and type-specific implications in cervical neoplasia. Vaccine. 2008;26(Suppl 10): K1-16.

4. Veldhuijzen NJ, Snijders PJ, Reiss P, Meijer CJ, van de Wijgert JH. Factors affecting transmission of mucosal human papillomavirus. Lancet Infect Dis. 2010;10(12):862-74.

5. Adebamowo SN, Olawande O, Famooto A, Dareng EO, Offiong R, Adebamowo CA, et al. Persistent low-risk and high-risk human papillomavirus infections of the uterine cervix in HIV-negative and HIVpositive women. Front Public Health. 2017;5:178.

6. Giuliano AR, Sedjo RL, Roe DJ, Harri R, Baldwi S, Papenfuss MR, et al. Clearance of oncogenic human papillomavirus (HPV) infection: effect of smoking (United States). Cancer Causes Control. 2002;13(9):839-46.

7. Adebamowo SN, Famooto A, Dareng EO, Olawande O, Olaniyan O, Offiong $\mathrm{R}$, et al. Clearance of type-specific, low-risk, and high-risk cervical human papillomavirus infections in HIV-negative and HIV-positive women. J Glob Oncol. 2018:4:1-12.

8. Castellsague $X$, Munoz N. Chapter 3: cofactors in human papillomavirus carcinogenesis--role of parity, oral contraceptives, and tobacco smoking. J Natl Cancer Inst Monogr. 2003:31:20-8.

9. Wang SS, Gonzalez P, Yu K, Porras C, Li Q, Safaeian M, et al. Common genetic variants and risk for HPV persistence and progression to cervical cancer. PLoS One. 2010;5(1):e8667. 
10. Safaeian M, Hildesheim A, Gonzalez P, Yu K, Porras C, Li Q, et al. Single nucleotide polymorphisms in the PRDX3 and RPS19 and risk of HPV persistence and cervical precancer/cancer. PLoS One. 2012;7(4):e33619.

11. Famooto A, Almujtaba M, Dareng E, Akarolo-Anthony S, Ogbonna C Offiong R, et al. RPS19 and TYMS SNPs and prevalent high risk human papilloma virus infection in Nigerian women. PLoS One. 2013;8(6):e66930.

12. Adebamowo SN, Ma B, Zella D, Famooto A, Ravel J, Adebamowo C, et al. Mycoplasma hominis and mycoplasma genitalium in the vaginal microbiota and persistent high-risk human papillomavirus infection. Front Public Health. 2017:5:140

13. Akarolo-Anthony SN, Al-Mujtaba M, Famooto AO, Dareng EO, Olaniyan OB,

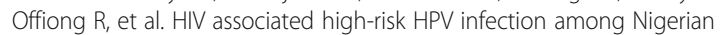
women. BMC Infect Dis. 2013;13:521.

14. Akarolo-Anthony SN, Famooto AO, Dareng EO, Olaniyan OB, Offiong R, Wheeler CM, et al. Age-specific prevalence of human papilloma virus infection among Nigerian women. BMC Public Health. 2014;14:656.

15. van Hamont D, van Ham MA, Bakkers JM, Massuger LF, Melchers WJ. Evaluation of the SPF10-INNO LiPA human papillomavirus (HPV) genotyping test and the roche linear array HPV genotyping test. J Clin Microbiol. 2006; 44(9):3122-9.

16. Kleter B, van Doorn LJ, Schrauwen L, Molijn A, Sastrowijoto S, ter Schegget $J$, et al. Development and clinical evaluation of a highly sensitive PCRreverse hybridization line probe assay for detection and identification of anogenital human papillomavirus. J Clin Microbiol. 1999;37(8):2508-17.

17. Melchers WJ, Bakkers JM, Wang J, de Wilde PC, Boonstra H, Quint WG, et al. Short fragment polymerase chain reaction reverse hybridization line probe assay to detect and genotype a broad spectrum of human papillomavirus types. Clinical evaluation and follow-up. Am J Pathol. 1999;155(5):1473-8.

18. McCarthy S, Das S, Kretzschmar W, Delaneau O, Wood AR, Teumer A, et al. A reference panel of 64,976 haplotypes for genotype imputation. Nat Genet. 2016;48(10):1279-83.

19. Loh PR, Danecek P, Palamara PF, Fuchsberger C, AR Y, KF H, et al. Referencebased phasing using the haplotype reference consortium panel. Nat Genet. 2016;48(11):1443-8.

20. Durbin R. Efficient haplotype matching and storage using the positional burrows-Wheeler transform (PBWT). Bioinformatics. 2014;30(9):1266-72.

21. Gurdasani D, Carstensen T, Tekola-Ayele F, Pagani L, Tachmazidou I, Hatzikotoulas K, et al. The African genome variation project shapes medical genetics in Africa. Nature. 2015;517(7534):327-32.

22. Gurdasani D, Carstensen T, Fatumo S, Chen G, Franklin CS, Prado-Martinez J, et al. Uganda genome resource enables insights into population history and genomic discovery in Africa. Cell. 2019;179(4):984-1002 e36.

23. Chang CC, Chow CC, Tellier LC, Vattikuti S, Purcell SM, Lee JJ. Secondgeneration PLINK: rising to the challenge of larger and richer datasets. Gigascience. 2015;4:7.

24. Purcell S, Chang C. PLINK 1.9.

25. Stelzer G, Rosen N, Plaschkes I, Zimmerman S, Twik M, Fishilevich S, et al. The GeneCards suite: from gene data mining to disease genome sequence analyses. Curr Protoc Bioinformatics. 2016;54:1-13.

26. Crosbie EJ, Einstein MH, Franceschi S, Kitchener HC. Human papillomavirus and cervical cancer. Lancet. 2013:382(9895):889-99.

27. Piersma SJ. Immunosuppressive tumor microenvironment in cervical cancer patients. Cancer Microenviron. 2011;4(3):361-75.

28. Stanley MA, Sterling JC. Host responses to infection with human papillomavirus. Curr Probl Dermatol. 2014:45:58-74.

29. Guan B, Li Q, Shen L, Rao Q, Wang Y, Zhu Y, et al. MicroRNA-205 directly targets Kruppel-like factor 12 and is involved in invasion and apoptosis in basal-like breast carcinoma. Int J Oncol. 2016;49(2):720-34.

30. Hoskins JW, Ibrahim A, Emmanuel MA, Manmiller SM, Wu Y, O'Neill M, et al. Functional characterization of a chr13q22.1 pancreatic cancer risk locus reveals long-range interaction and allele-specific effects on DIS3 expression. Hum Mol Genet. 2016;25(21):4726-38

31. Yao H, Xia D, Li ZL, Ren L, Wang MM, Chen WS, et al. MiR-382 functions as tumor suppressor and chemosensitizer in colorectal cancer. Biosci Rep. 2018:39:BSR20180441.

32. Mak CS, Yung MM, Hui LM, Leung LL, Liang R, Chen $K$, et al. MicroRNA-141 enhances anoikis resistance in metastatic progression of ovarian cancer through targeting KLF12/Sp1/survivin axis. Mol Cancer. 2017;16(1):11.

33. Frankel A, Armour N, Nancarrow D, Krause L, Hayward N, Lampe G, et al. Genome-wide analysis of esophageal adenocarcinoma yields specific copy number aberrations that correlate with prognosis. Genes Chromosom Cancer. 2014:53(4):324-38.

34. Sun KY, Peng T, Chen Z, Song P, Zhou XH. Long non-coding RNA LOC100129148 functions as an oncogene in human nasopharyngeal carcinoma by targeting miR-539-5p. Aging (Albany NY). 2017;9(3):999-1011.

35. el Awady MK, Kaplan JB, O'Brien SJ, Burk RD. Molecular analysis of integrated human papillomavirus 16 sequences in the cervical cancer cell line SiHa. Virology. 1987;159(2):389-98.

36. Hu Z, Zhu D, Wang W, Li W, Jia W, Zeng X, et al. Genome-wide profiling of HPV integration in cervical cancer identifies clustered genomic hot spots and a potential microhomology-mediated integration mechanism. Nat Genet. 2015;47(2):158-63.

37. O'Leary NA, Wright MW, Brister JR, Ciufo S, Haddad D, McVeigh R, et al. Reference sequence (RefSeq) database at NCBI: current status, taxonomic expansion, and functional annotation. Nucleic Acids Res. 2016;44(D1):D733-45.

38. Gee JM, Shaw VE, Hiscox SE, McClelland RA, Rushmere NK, Nicholson RI. Deciphering antihormone-induced compensatory mechanisms in breast cancer and their therapeutic implications. Endocr Relat Cancer. 2006; 13(Suppl 1):S77-88.

39. Pan S, Cheng L, White JT, Lu W, Utleg AG, Yan X, et al. Quantitative proteomics analysis integrated with microarray data reveals that extracellular matrix proteins, catenins, and p53 binding protein 1 are important for chemotherapy response in ovarian cancers. OMICS. 2009;13(4): 345-54.

40. Deiss LP, Feinstein E, Berissi $H$, Cohen $O$, Kimchi A. Identification of a novel serine/threonine kinase and a novel $15-\mathrm{kD}$ protein as potential mediators of the gamma interferon-induced cell death. Genes Dev. 1995;9(1):15-30.

41. Koren I, Reem E, Kimchi A. DAP1, a novel substrate of mTOR, negatively regulates autophagy. Curr Biol. 2010;20(12):1093-8.

42. Nagy R, Boutin TS, Marten J, Huffman JE, Kerr SM, Campbell A, et al. Exploration of haplotype research consortium imputation for genome-wide association studies in 20,032 generation Scotland participants. Genome Med. 2017:9(1):23.

43. Anderson CA, Boucher G, Lees CW, Franke A, D'Amato M, Taylor KD, et al. Meta-analysis identifies 29 additional ulcerative colitis risk loci, increasing the number of confirmed associations to 47. Nat Genet. 2011;43(3):246-52.

44. Liu JZ, van Sommeren S, Huang H, Ng SC, Alberts R, Takahashi A, et al. Association analyses identify 38 susceptibility loci for inflammatory bowel disease and highlight shared genetic risk across populations. Nat Genet. 2015;47(9):979-86.

45. Comuzzie AG, Cole SA, Laston SL, Voruganti VS, Haack K, Gibbs RA, et al. Novel genetic loci identified for the pathophysiology of childhood obesity in the Hispanic population. PLoS One. 2012;7(12):e51954.

46. Wazir U, Jiang WG, Sharma AK, Mokbel K. The mRNA expression of DAP1 in human breast cancer: correlation with clinicopathological parameters. Cancer Genomics Proteomics. 2012;9(4):199-201.

47. Torabi A, Ordonez J, Su BB, Palmer L, Mao C, Lara KE, et al. Novel somatic copy number alteration identified for cervical cancer in the Mexican American population. Med Sci (Basel). 2016;4(3):1.

48. Vazquez-Mena O, Medina-Martinez I, Juarez-Torres E, Barron V, Espinosa A, Villegas-Sepulveda N, et al. Amplified genes may be overexpressed, unchanged, or downregulated in cervical cancer cell lines. PLoS One. 2012; 7(3):e32667.

49. Esteller M. Epigenetic lesions causing genetic lesions in human cancer: promoter hypermethylation of DNA repair genes. Eur J Cancer. 2000;36(18): 2294-300.

50. Li M, Liu L, Zang W, Wang Y, Du Y, Chen X, et al. miR365 overexpression promotes cell proliferation and invasion by targeting ADAMTS-1 in breast cancer. Int J Oncol. 2015;47(1):296-302

51. Mollaei H, Safaralizadeh R, Babaei E, Abedini MR, Hoshyar R. The antiproliferative and apoptotic effects of crocin on chemosensitive and chemoresistant cervical cancer cells. Biomed Pharmacother. 2017;94:307-16.

52. Guo SL, Ye H, Teng Y, Wang YL, Yang G, Li XB, et al. Akt-p53-miR-365-cyclin D1/cdc25A axis contributes to gastric tumorigenesis induced by PTEN deficiency. Nat Commun. 2013:4:2544.

53. Hamada S, Masamune A, Miura S, Satoh K, Shimosegawa T. MiR-365 induces gemcitabine resistance in pancreatic cancer cells by targeting the adaptor protein SHC1 and pro-apoptotic regulator BAX. Cell Signal. 2014:26(2):179-85. 
54. Chen Z, Huang Z, Ye Q, Ming Y, Zhang S, Zhao Y, et al. Prognostic significance and anti-proliferation effect of microRNA-365 in hepatocellular carcinoma. Int J Clin Exp Pathol. 2015;8(2):1705-11.

55. Nie J, Liu L, Zheng W, Chen L, Wu X, Xu Y, et al. microRNA-365, downregulated in colon cancer, inhibits cell cycle progression and promotes apoptosis of colon cancer cells by probably targeting Cyclin D1 and Bcl-2. Carcinogenesis. 2012;33(1):220-5.

56. Qi J, Rice SJ, Salzberg AC, Runkle EA, Liao J, Zander DS, et al. MiR-365 regulates lung cancer and developmental gene thyroid transcription factor 1. Cell Cycle. 2012;11(1):177-86.

57. Sun R, Liu Z, Ma G, Lv W, Zhao X, Lei G, et al. Associations of deregulation of mir-365 and its target mRNA TTF-1 and survival in patients with NSCLC. Int J Clin Exp Pathol. 2015;8(3):2392-9.

58. Zhou L, Gao R, Wang Y, Zhou M, Ding Z. Loss of BAX by miR-365 promotes cutaneous squamous cell carcinoma progression by suppressing apoptosis. Int J Mol Sci. 2017;18(6):1.

59. Singh R, Saini N. Downregulation of BCL2 by miRNAs augments druginduced apoptosis--a combined computational and experimental approach. J Cell Sci. 2012:125(Pt 6):1568-78.

60. Venteclef N, Jakobsson T, Ehrlund A, Damdimopoulos A, Mikkonen L, Ellis E, et al. GPS2-dependent corepressor/SUMO pathways govern antiinflammatory actions of LRH-1 and LXRbeta in the hepatic acute phase response. Genes Dev. 2010;24(4):381-95.

61. Cai YN, Zhou Q, Kong YY, Li M, Viollet B, Xie YH, et al. LRH-1/hB1F and HNF1 synergistically up-regulate hepatitis $B$ virus gene transcription and DNA replication. Cell Res. 2003;13(6):451-8.

62. Fayard E, Auwerx J, Schoonjans K. LRH-1: an orphan nuclear receptor involved in development, metabolism and steroidogenesis. Trends Cell Biol. 2004;14(5):250-60

63. Petersen GM, Amundadottir L, Fuchs CS, Kraft P, Stolzenberg-Solomon RZ, Jacobs KB, et al. A genome-wide association study identifies pancreatic cancer susceptibility loci on chromosomes 13q22.1, 1q32.1 and 5p15.33. Nat Genet. 2010;42(3):224-8.

64. Wang SL, Zheng DZ, Lan FH, Deng XJ, Zeng J, Li CJ, et al. Increased expression of hLRH-1 in human gastric cancer and its implication in tumorigenesis. Mol Cell Biochem. 2008;308(1-2):93-100.

65. Chand AL, Herridge KA, Thompson EW, Clyne CD. The orphan nuclear receptor $\mathrm{LRH}-1$ promotes breast cancer motility and invasion. Endocr Relat Cancer. 2010;17(4):965-75.

66. Lin Q, Aihara A, Chung W, Li Y, Chen X, Huang Z, et al. LRH1 promotes pancreatic cancer metastasis. Cancer Lett. 2014;350(1-2):15-24.

67. Nadolny C, Dong X. Liver receptor homolog-1 (LRH-1): a potential therapeutic target for cancer. Cancer Biol Ther. 2015;16(7):997-1004.

68. Kramer HB, Lai CF, Patel H, Periyasamy M, Lin ML, Feller SM, et al. LRH-1 drives colon cancer cell growth by repressing the expression of the CDKN1A gene in a p53-dependent manner. Nucleic Acids Res. 2016;44(2): 582-94

69. Dube C, Bergeron F, Vaillant MJ, Robert NM, Brousseau C, Tremblay JJ. The nuclear receptors SF1 and LRH1 are expressed in endometrial cancer cells and regulate steroidogenic gene transcription by cooperating with AP-1 factors. Cancer Lett. 2009;275(1):127-38.

70. Azad AK, Bairati I, Qiu X, Girgis H, Cheng L, Waggott D, et al. A genomewide association study of non-HPV-related head and neck squamous cell carcinoma identifies prognostic genetic sequence variants in the MAPkinase and hormone pathways. Cancer Epidemiol. 2016;42:173-80.

71. Wang Z, Hildesheim A, Wang SS, Herrero R, Gonzalez P, Burdette L, et al. Genetic admixture and population substructure in Guanacaste Costa Rica. PLoS One. 2010;5(10):e13336.

72. Ward LD, Kellis M. HaploReg: a resource for exploring chromatin states, conservation, and regulatory motif alterations within sets of genetically linked variants. Nucleic Acids Res. 2012;40(Database issue):D930-4.

\section{Publisher's Note}

Springer Nature remains neutral with regard to jurisdictional claims in published maps and institutional affiliations.

\section{Ready to submit your research? Choose BMC and benefit from:}

- fast, convenient online submission

- thorough peer review by experienced researchers in your field

- rapid publication on acceptance

- support for research data, including large and complex data types

- gold Open Access which fosters wider collaboration and increased citations

- maximum visibility for your research: over $100 \mathrm{M}$ website views per year

At BMC, research is always in progress.

Learn more biomedcentral.com/submissions 